\title{
Environmental impact assessment for ionising radiation within the Arctic
}

\author{
A. Hosseini and J.E. Brown \\ Norwegian Radiation Protection Authority, PO Box 55, 1332 Østeras, Norway
}

\begin{abstract}
The Arctic environment is unique in terms of many factors that may influence the behaviour and fate of contaminants including the presence of permafrost, low temperatures, slow breakdown of organic compounds, short food chains and long recovery times for some species. This study introduces the issues surrounding the development of a bespoke environmental impact assessment methodology specifically for the consideration of radiation impacts on Arctic ecosystems. The approach allows for the impact on plants and animals from exposure to radiation to be quantified in a robust manner through integration of our current knowledge concerning transfer in the environment, resultant dose-rates from the presence of radioactivity within biota and their media and information concerning radiobiological effects on endpoints of concern from an environmental protection perspective.
\end{abstract}

\section{INTRODUCTION}

There is increasing concern over potential radioactive contamination of the Arctic due to the presence of a wide range of nuclear sources within and in proximity to this region. In the public perception, the Arctic might be considered as an "untouched" environment and, in many areas, one where any introduction of pollutants would be seen as adverse [1]. However, at the scientific level, there are other considerations that make the Arctic an interesting study case. There is evidence to suggest that the in situ physical conditions in the Arctic may hypothetically alter radionuclide transfer to biota [2], at least in the case of poikilotherms. The modifying influence of Arctic climatic conditions upon the expression of radiation induced effects has also been hypothesised by [3]. Furthermore, low temperatures, extreme seasonal variations in incoming solar radiation and lack of nutrients are physical and chemical environmental stressors of Arctic organisms which limit biodiversity. These also make Arctic ecosystems potentially more vulnerable to contaminants than organisms in other European climatic regions [4].

Methodologies to assess the impact of exposure to ionising radiation on flora and fauna in European temperate and Arctic environments have been developed in two European collaborative projects "FASSET - Framework for Assessment of Environmental Impact" [5] and "EPIC - Environmental Protection from Ionizing Contaminants in the Arctic" [6] respectively. The latter project provides a number of the foundation stones that are prerequisite in the process of developing a robust assessment methodology for the Arctic. However, the development of the EPIC framework was curtailed at a point that does not allow for risk characterisation or concomitant management options. These programmes have been superseded by the project "ERICA - Environmental Risk from Ionising Contaminants: Assessment and Management" wherein risk assessment methodologies have been developed and issues relevant to decision making in the context of the management of environmental impacts of radioactivity have been addressed [7].

Drawing on the additional components and methodologies recently developed within the ERICA project and using EPIC as a foundation and by way of example, the following sections will address the question of how a full environmental assessment including risk characterisation might be conducted for the Arctic. 


\section{ASSESSMENT SYSTEM: AN OVERVIEW}

Generally, assessment systems are constructed of five separate stages: planning, problem formulation, assessment, risk characterisation and decision and management (see Figure 1). All components, with the exception of Decision and Management, will be addressed in this paper, although, the main emphasis will be placed upon the assessment and risk characterisation parts.

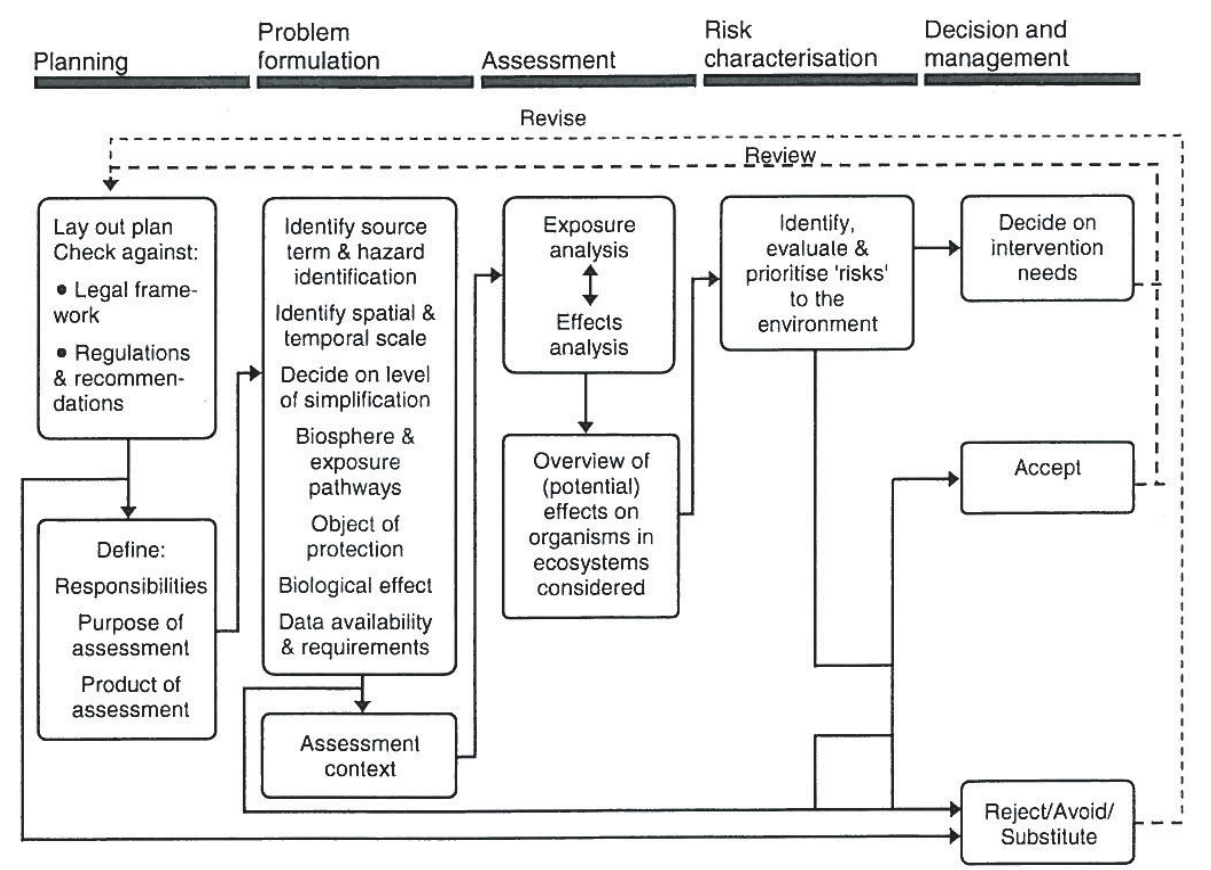

Figure 1. Elements in a stepwise environmental assessment and management framework [5].

\section{LEGAL AND ETHICAL CONCERNS}

Any plan for conducting an environmental risk assessment will generally need to be checked with underlying principles and international regulations. This is necessary in order to facilitate compatibility with legislative requirement at national levels. However, the Arctic consists of territories of various nations, and as such has no overall and binding legal regime. As elsewhere, the framework for environmental protection of the Arctic is constituted by national laws. However, global treaties and norms to a larger and larger extent influence national laws - something that is undoubtedly linked to the special status of the Arctic environment discussed above. In particular, international marine treaties have influenced the domestic laws, and much of the focus of environmental protection of the Arctic has therefore been marine conservation [6].

Regarding the ethical concerns which may arise upon the development of a system of protection, the International Atomic Energy Agency [8] has identified five basic principles, which reflect an international view or overlapping consensus. These are: conservation of habitat and species; maintenance of biodiversity; sustainability; environmental justice; and human dignity. 


\section{PROBLEM FORMULATION}

The starting point for most assessment, following an extrinsic planning phase, will be the problem formulation. At this stage information on the following categories might be collated:

(i) The radionuclides to be considered within the assessment;

(ii) the environmental transfer and fate of selected radionuclides through aquatic and terrestrial ecosystems in the Arctic;

(iii) the process of identifying reference Arctic biota that can be used to evaluate potential dose rates to biota in different environments;

(iv) compilation of data on dose-effects relationships.

This information provides the background and working materials for the assessment phase.

\section{RADIONUCLIDE TRANSFER TO BIOTA}

The starting point for the assessment can be selected to be a unit concentration in the organisms' habitat, i.e. $\mathrm{Bq} \mathrm{l}^{-1}, \mathrm{~Bq} \mathrm{~kg}^{-1}$ or $\mathrm{Bq} \mathrm{m}^{-2}$. In the absence of monitoring data, it is assumed that the assessor will have access to appropriate models to allow activity concentrations in abiotic compartments of the environment, i.e. water, soil and/or sediment, to be calculated. The approach used in EPIC [6] and the more recent ERICA project $[9,10]$ in the derivation of biota concentrations from known media concentrations involves the use of equilibrium concentration ratios (CR). In the latter case, even though the generated CR databases are of more generic character, they may still prove useful in both providing Arctic relevant transfer data and methods pertinent to derivation of statistical information.

An extensive review on transfer factors was undertaken in the EPIC project [11] comprising of more than 300 publications (refereed literature, books, institute reports and conference proceedings) for the terrestrial environment, over 1300 data entries for the marine (covering $\mathrm{Cs}$, Sr, Tc and $\mathrm{Pu}$ and 7 reference organism groups) and a modest review in the freshwater environment where $\mathrm{CR}$ values for ${ }^{137} \mathrm{Cs}$ (water $\rightarrow$ muscle) and ${ }^{90} \mathrm{Sr}$ (water $\rightarrow$ bone) have been provided for 4 species of fish from Arctic Russian lakes.

Where data are lacking on some of the parameters required for simulation of transfer, allometric relationships may provide surrogate values. The allometric approach is based on the observation that metabolic parameters, including basal metabolic rates, ingestion rates, biological half times etc., are proportional to the mass of an organism. Such models have been applied to Arctic environments for the purpose of simulating transfer. The application of a multi-compartmental model, parameterised using allometrically derived values where appropriate, has allowed the derivation of $\mathrm{Cs}$ and $\mathrm{Pu} \mathrm{CRs}$ for several Arctic marine trophic levels [12]. The preliminary estimates agreed well with empirical datasets and demonstrated that, in some cases, the application of an equilibrium CR was highly inappropriate.

\section{ABSORBED DOSE RATES}

The basic components of information that are required to derive dose rates to organisms are:

(i) the activity concentrations of radionuclides in (selected) reference biota and their habitat;

(ii) Dose Conversion Coefficients (DCCs) mapping these activity concentrations onto a dose rate and

(iii) occupancy factors defining the time spent by biota in various surroundings within their habitats for the parameterisation of external dose calculations.

The dosimetric methods developed in EPIC [13] have been superseded by the calculation tools that are now available from the culmination of the project ERICA. Within the ERICA Assessment Tool [14] it is possible to derive user defined geometries representing a given plant or animal and thereafter derive radionuclide specific DCCs. These are, furthermore, the methods that have currently been adopted by 
the ICRP in the derivation of DCCs specifically for Reference Animal and Plants (RAPs). It should be noted that these newly available dosimetric methods have not been applied for the purpose of Arctic radiation protection frameworks. Little effort would be required to run the aforementioned dosimetric module for the lists of reference organisms generated in the EPIC project in order to bring the DCC values in line with those used by ERICA and moreover the ICRP.

\section{IDENTIFICATION AND MANAGEMENT OF DATA GAPS}

The exposure assessment as it is presented above relies on comprehensive underpinning databases providing information on transfer through the use of CRs and dose-rates per unit concentration through the application of dose conversion coefficients. Data gaps may arise because the selected reference organism (as applied in the EPIC and ERICA approach) does not adequately represent the organism(s) of particular interest within a given study or because the radioisotope to be assessed does not form part of the default databases. The flexibility available within the recently developed ERICA Tool [14] allows these potential obstacles to be navigated in a reasonably robust manner. For filling gaps in transfer data, guidance is available (see, e.g. [9, 10]). These data gap filling methods have not been applied in any structured way to the Arctic environment. The application of such methods would provide a more robust foundation for future assessments in the Arctic and would harmonise the methods for Arctic environment with those used for temperate or world-generic systems.

\section{PLACING THE EXPOSURE ESTIMATIONS IN CONTEXT}

There are essentially two points of reference for the purpose of assessing the potential consequences of exposures to radiation on non-human biota. These are (a) natural background dose rates and (b) dose rates known to have specific biological effects on individual organisms [15]. Bands of derived consideration levels for reference fauna and flora are also proposed by ICRP and these could be compiled by combining information on logarithmic bands of dose rates relative to normal natural background dose rates, in conjunction with information on dose rates that may have an adverse effect on reproductive success, or result in early mortality (or cause morbidity), or are likely to result in scorable DNA damage for such organisms [16].

The typical dose rates of natural background exposure for different types of organisms in the Arctic are discussed by [3]. These dose rates have been derived using data on the activity concentrations of natural radionuclides in the Arctic aquatic ecosystems for several reference organism groups. Terrestrial background radiation dose-rates have been particularly poorly characterised. However, some new information on terrestrial background dose-rates is likely to become available through the work of [17] but as is often the case, the dose-rates derived are based primarily on information from temperate environments. Whether these values are directly relevant for Arctic systems is debatable.

Although direct data on radiation effects in the Arctic are rather scarce, some peculiarities in manifestation of radiation effects can be expected in the Arctic organisms as oppose to organisms inhabiting temperate environments. The development of radiation effects in Arctic poikilothermic (or hibernating) organisms is expected to occur more slowly, because of low environmental temperatures. On the other hand, the repair of radiation damage in cells and tissues is not effective at very low temperatures. Lesions in the cooled organisms (e.g. poikilothermic or hibernating animals) are latent. However, if organisms become warm, lesions are rapidly revealed. As a result, radiation effects may not appear during the winter period, and manifest themselves intensively during the warm season. High concentrations of lipids in the Arctic animals may be expected to increase the radiosensitivity, since chemical products of lipidoperoxidation produced by irradiation are toxic for organisms [3].

Many of the data generated in the EPIC project have been included within the ERICA effect database, FREDERICA [18]. Although the database mostly includes information on plants and animals that are not indigenous to the Arctic, it still constitutes an important source of reference in the evaluation 
of any environmental impact arising from radiation exposure in the Arctic. However, the extrapolation of dose-effects data from predominately temperate conditions to the severe conditions associated with the Arctic may require some caution and, in the case of deriving limits, the application of appropriate safety factors.

\section{RISK CHARACTERISATION}

In order to estimate the probability, including concomitant uncertainties, of effects in the environment from exposures to ionising radiation, probabilistic approaches can be applied. Such methods require the assignment of probability distribution functions (pdfs) to uncertain variables. There are a number of ways of assigning a pdf, inter alia, distribution fitting, maximum entropy method, Bayesian inference and expert elicitation. The method to choose depends upon the availability and quality of data and the appropriate probability distribution type should be selected on a case-by-case basis. However, experience has shown that the uncertainty of radioecological data e.g. concentration ratios (CRs) and distribution coefficients $\left(\mathrm{K}_{\mathrm{d}} \mathrm{s}\right)$, are often well fitted by lognormal distributions.

Once parameters have been assigned suitable distributions, Monte Carlo analysis may be used to quantify the uncertainties of the estimations by propagating the uncertainties in the input and parameters through the model. The approach outlined here has been applied within the framework of the ERICA project as discussed by [19].This approach has currently not been applied to the Arctic for lack of underlying information that might allow pdfs to be defined for the parameters used in the risk characterisation. Primarily this point relates to the lack of statistical information for the CR values collated within the EPIC project.

\section{AVAILABLE ASSESSMENT TOOLS}

Software tools are available that allow environmental impact assessments to be conducted in a structured self-contained manner. The 2 most pertinent examples are given below:

- The RESRAD-BIOTA code (available from http://www.ead.anl.gov/resrad) was designed to be consistent with, and provide a tool for, implementing the graded approach for biota dose assessment [20]. The code includes a kinetic-allometric approach to estimate the transfer of radionuclides to animals.

- The ERICA Tool is a computerised, flexible software system that has a structure based upon the ERICA Integrated Assessment tiered approach to assessing the radiological risk to biota (available from http://www.project.facilia.se/erica/download.html). The Tool guides the user through the assessment process, recording information and decisions and allowing the necessary calculations to be performed to estimate risks to selected biota. Results from the Tool can be put into context using incorporated data on dose-effects relationships and background dose-rates [14].

Either one of these tools could be applied to Arctic environments for selected scenarios in a straightforward manner. This would require, however, an adaptation of existing parametric data to account for Arctic specific conditions, primarily in relation to transfer datasets and dosimetric parameters reflecting Arctic reference organisms.

\section{NEEDS FOR FURTHER DEVELOPMENT OF ASSESSMENT METHODOLOGY}

Despite the availability of large data sets, there exist considerable information gaps with regards to transfer of radionuclides in the Arctic environment and the effects of chronic exposure on the Arctic wildlife. Existing data concerning transfer in Arctic environment have not been collated in such a way as to lend themselves to probabilistic approaches. Nor have the most recently developed dosimetric methods been applied to the situation present in the Arctic. Hypothesis concerning the greater vulnerability of Arctic plants and animals to exposures to ionising radiation have not been tested nor 
have background dose rates to biota in Arctic environments been derived in a robust way. Methods have been applied in temperate environments in order to derive screening dose rates designed to be protective of sensitive endpoints in generic ecosystems. Such methods might be adapted for use in the Arctic by selection of appropriate effects data and application of bespoke uncertainty factors.

\section{Acknowledgments}

This work was supported by the Norwegian Research Council (NFR) and forms part of the INTRANOR (Impact assessment of elevated levels of natural/technogenic radioactivity on wildlife of the North) project, contract number 185134. The financial support of the NFR is gratefully acknowledged.

\section{References}

[1] Oughton, D.H., Ethics, philosophy and environmental protection in the Arctic: A case study on harmonisation of chemical and radioactive pollutant management. In: Environmental Radioactivity in the Arctic and Antarctic, (editors, P. Strand, T. Jolle, A. Sand), Published by: NRPA: Østerås. ISBN 82-90362-13-7. (2002) pp. 31-34.

[2] Sazykina, T.G., Radiation Protection Dosimetry, 75 (1998), 219-222.

[3] Sazykina, T.G., Jaworska, A. and Brown, J.E. (Eds.). A Deliverable Report (D5) of the EPIC project (Contract no. ICA2-CT-200-10032). (2003) pp. 119.

[4] AMAP, Assessment Report: Arctic Pollution Issues, Oslo (1998) pp. 859.

[5] Larsson, C-M., J. Radiol. Prot., 24 (2004), pp. A1-A13.

[6] Brown, J.E., Thørring, H. and Hosseini, A., A Deliverable Report (D6) of the EPIC project (Contract no. ICA2-CT-200-10032). (2003) pp. 175.

[7] Beresford, N., Brown, J., Copplestone, D., Garnier-Laplace, J., Howard, B., Larsson, C-M., Oughton, D., Pröhl, G and Zinger. I., D ERICA: A Deliverable Report for the Project ERICA (Contract No. FI6R-CT-2004-508847) (2007) pp. 82.

[8] IAEA, TECDOC-1270. International Atomic Energy Agency, Vienna (2002) pp. 36.

[9] Hosseini A., Thørring H., Brown, J.E., Saxén R. and Ilus, E. J. Env. Rad. (in press) (2008).

[10] Beresford, N.A., Barnett, C.L., Howard, B.J., Scott, A., Brown, J. and Copplestone, D. J. Env. Rad. (in press) (2008).

[11] Beresford, N.A., Wright, S.M., Brown, J.E. and Sazykina, T. (Eds.). A Deliverable Report (D3) for the EPIC project (EC Inco-Copernicus project ICA2-CT-2000-10032) (2003) pp. 75.

[12] Brown, J.E., Børretzen, P., Dowdall, M., Sazykina, T. and Kryshev, I., Marine Biota Arctic, 57 (No.3) (2004) pp. 279-289.

[13] Golikov, V. and Brown, J.E. (Eds.). A Deliverable Report (D4) for the EPIC project (EC IncoCopernicus project ICA2-CT-2000-10032) (2003) pp. 52.

[14] Brown, J.E., Alfonso, B., Avila, R., Beresford, N.A., Copplestone, D., Pröhl, G. and Ulanovsky, A. J. Env. Rad. (in press) (2008).

[15] Pentreath, R. J., J. Radiol. Prot., 22 (2002) 45-56.

[16] ICRP, Annals of the ICRP 91 (2003) 201-266.

[17] Beresford, N.A., Barnett, C.L., Jones, D., Wood, M., Appleton, D., Breward, N. and Copplestone, D.C., J. Env. Rad. (in press) (2008).

[18] Copplestone, D., Hingston, J. and Real, A. J. Env. Rad. (in press) (2008).

[19] Zinger I., (Ed.). A Deliverable Report (D8) for the Project ERICA (Contract No. FI6R-CT-2004508847) (2007) pp. 127.

[20] USDOE (2002).Technical Standard DOE-STD-1153-2002. U.S. Department of Energy, Washington D.C. 